\title{
Brown Dog Tick, Rhipicephalus sanguineus Latreille (Arachnida: Acari: Ixodidae) ${ }^{1}$
}

C. C. Lord $^{2}$

\section{Introduction}

The brown dog tick, Rhipicephalus sanguineus Latreille, is unusual among ticks, in that it can complete its entire life cycle indoors. Because of this, it can establish populations in colder climates, and has been found in much of the world. Many tick species can be carried indoors on animals, but cannot complete their entire life cycle inside. Although $R$. sanguineus will feed on a wide variety of mammals, dogs are the preferred host in the US and appear to be required to develop large infestations.

Infestations in houses can explode to very high levels quickly. Typically, a few ticks are brought into the house or kennel, often on a dog which has been away from home. The early stages of the infestation, when only a few individuals are present, are often missed completely. The first indication the dog owner has that there is a problem is when they start noticing ticks crawling up the walls or curtains!

\section{Distribution}

The tick is found world-wide, more commonly in warmer climates. It is present throughout Florida, and is found on dogs, in kennels and houses, and occasionally on wildlife.

\section{Description and Identification}

Among ticks in Florida, this tick is easily recognized. It is small, red-brown in color (called the red dog tick in other parts of the world), and lacking any ornamentation. Although not sufficient for formal identification, it can be recognized by its by red-brown color, elongated body shape, and hexagonal basis capituli. The hexagonal basis capituli is a particularly good identifying character, as only one other tick species with this feature has ever been found in Florida (Boophilus annulatus, the cattle tick). The cattle tick was eradicated from Florida many years ago, so ticks found in Florida now with a hexagonal basis captituli are almost certainly $R$. sanguineus.

\section{Hosts}

In the US, the brown dog tick prefers to feed on dogs in all stages. However, it will feed on other mammals, including domestic animals and humans. This is most likely to occur if it can't find a dog nearby, so beware of trying to control the tick by

1. This document is EENY-221, one of a series of Featured Creatures from the Entomology and Nematology Department, Florida Cooperative Extension Service, Institute of Food and Agricultural Sciences, University of Florida. Published: July 2001. This document is also available on Featured Creatures Website at http://creatures.ifas.ufl.edu. Please visit the EDIS Website at http://edis.ifas.ufl.edu.

2. C. C. Lord, associate professor, Florida Meidcal Entomology Laboratory, University of Florida, Vero Beach, FL.

The Institute of Food and Agricultural Sciences (IFAS) is an Equal Employment Opportunity - Affirmative Action Employer authorized to provide research, educational information and other services only to individuals and institutions that function without regard to race, creed, color, religion, age, disability, sex, sexual orientation, marital status, national origin, political opinions or affiliations. For information on obtaining other extension publications, contact your county Cooperative Extension Service office. Florida Cooperative Extension Service / Institute of Food and Agricultural Sciences / University of Florida / Larry R. Arrington, Interim Dean 


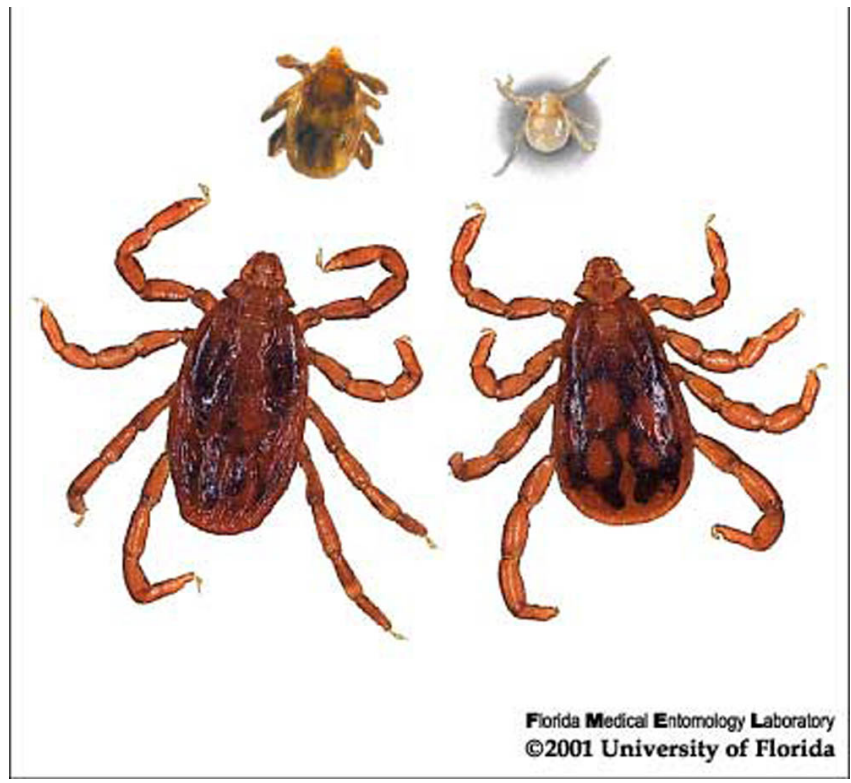

Figure 1. Stages of the brown dog tick, Rhipicephalus sanguineus Latreille. Clockwise from top, larva, male, female, nymph. Credits: James Newman, University of Florida

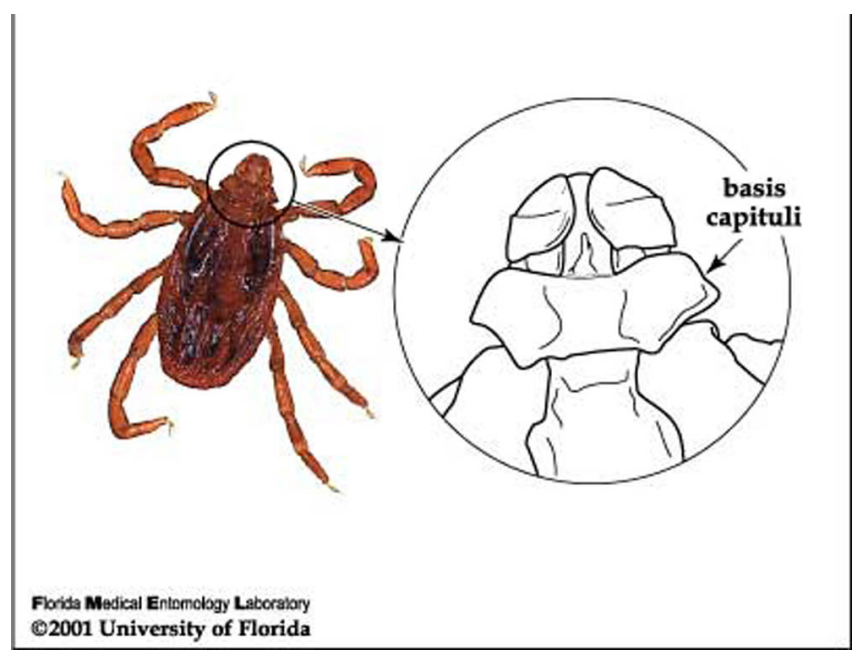

Figure 2. Hexagonal basis capituli, an identifying character for the brown dog tick, Rhipicephalus sanguineus Latreille. Credits: James Newman, University of Florida

removing the dogs! Elsewhere in the world, it is more frequently found feeding on other mammals. This difference in host preference is not completely understood, but is probably related to the animals available and differences in the populations from the original introductions into new areas. In the southeastern US, it has been reported occasionally from rodents and deer, but most collections are from dogs and (much less commonly) humans.

\section{Life Cycle}

Ixodid ticks require three blood meals to complete development; once each as a larva, nymph and adult. The brown dog tick is a 3-host tick; this indicates that it leaves the host to develop and molt between the larval, nymphal and adult stages. Each stage must locate a host; in a domestic environment this may result in feeding on the same dog (if there is only one or a few dogs present), but there is an opportunity for the same tick to feed on three different hosts.

A fully blood-fed female brown dog tick can lay up to 5000 eggs; the number of eggs laid depends on the size of the tick and the amount of blood she ingested. The length of time each stage feeds, and the time required for development and molting, are very dependent on temperature. Feeding and development times are generally faster at warmer temperatures. Survival is generally higher at cooler temperatures and higher relative humidity, but these ticks are tolerant of a wide range in conditions.

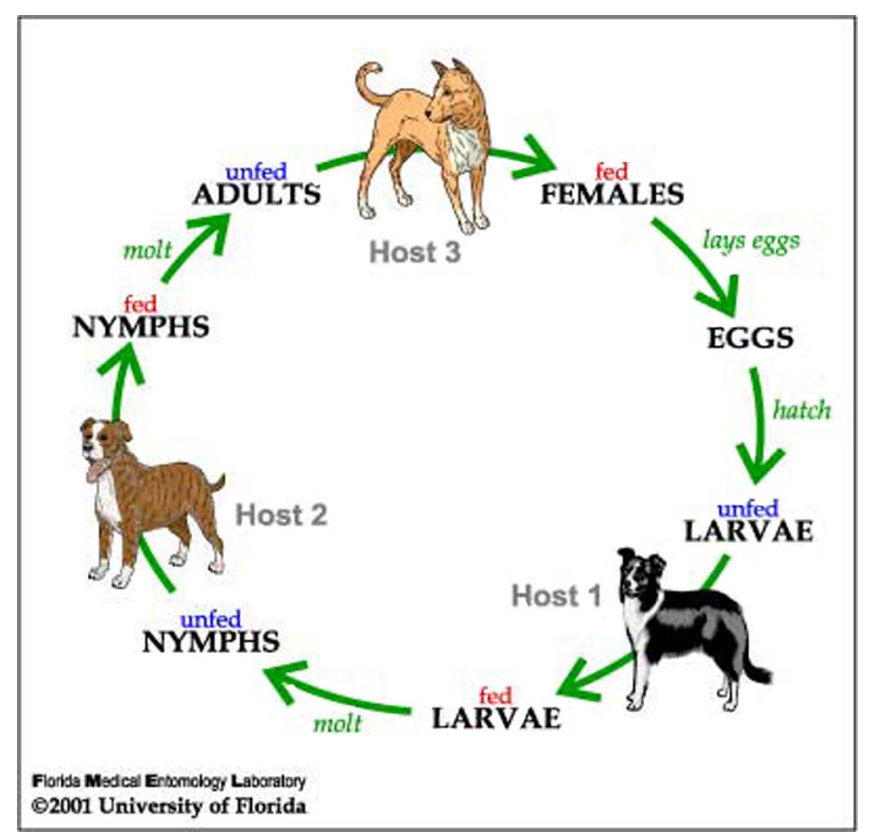

Figure 3. Life cycle of the brown dog tick, Rhipicephalus sanguineus Latreille. Credits: James Newman, University of Florida

An adult female will feed on the host for around one week, then drop off the host and find a secluded place for egg development. Cracks and crevices in houses, garages and dog runs are ideal locations. She will start laying as soon as four days after she 
completes feeding and drops off the host, and can continue to lay for as long as 15 days. As she lays the eggs, she passes them over her porose areas (specialized areas on the back of the basis capituli), to coat them in secretions which protect the eggs from drying out. After she finishes laying her eggs, she dies. The larvae hatch two to five weeks later, and begin to quest, or look for a host. All stages of this tick prefer dogs, although they will feed on other mammals. Larvae feed for three to seven days, then take about two weeks to develop into nymphs. The nymphs then feed for five to 10 days and again take about two weeks to develop into adults. As adults, both males and females will attach to hosts and feed, although the males only feed for short periods. The overall cycle can be completed in just over two months, but frequently will take longer if there are few hosts available or in cold temperatures. Ticks are notoriously long-lived, and can live as long as three to five months in each stage without feeding.

In Florida, the cycle can occur year-round both inside houses and in outside kennels and dog runs.

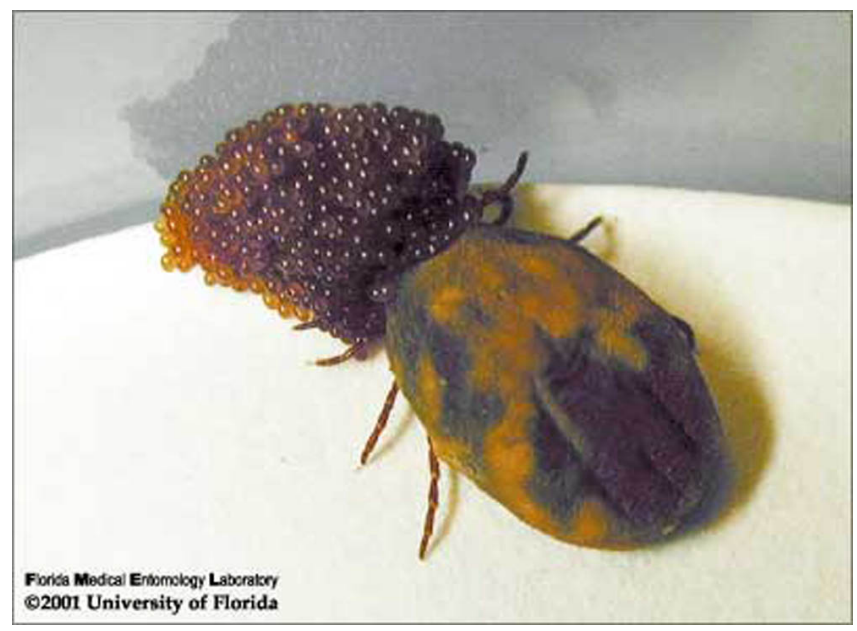

Figure 4. Female brown dog tick, Rhipicephalus sanguineus Latreille, laying eggs. Credits: James Newman and Leah LeFevre, University of Florida

Frequently, people report having different types of ticks, or adults and "babies". In fact, generally what they are seeing are engorged and unengorged ticks or different stages. Ticks increase in size dramatically while feeding; engorged ticks are considerably larger than unengorged ticks. The different stages (larva, nymph and adult) are progressively larger in size. Many features used to identify the stages and sexes are difficult to see without a microscope. Larvae have only six legs, while nymphs and adults have eight. Males and females are difficult to distinguish without examining them microscopically, but males take only small blood meals while females take large meals and increase in size. Nymphs are distinguishable from adults primarily by size, but this is not reliable and needs to be confirmed by microscopic examination.

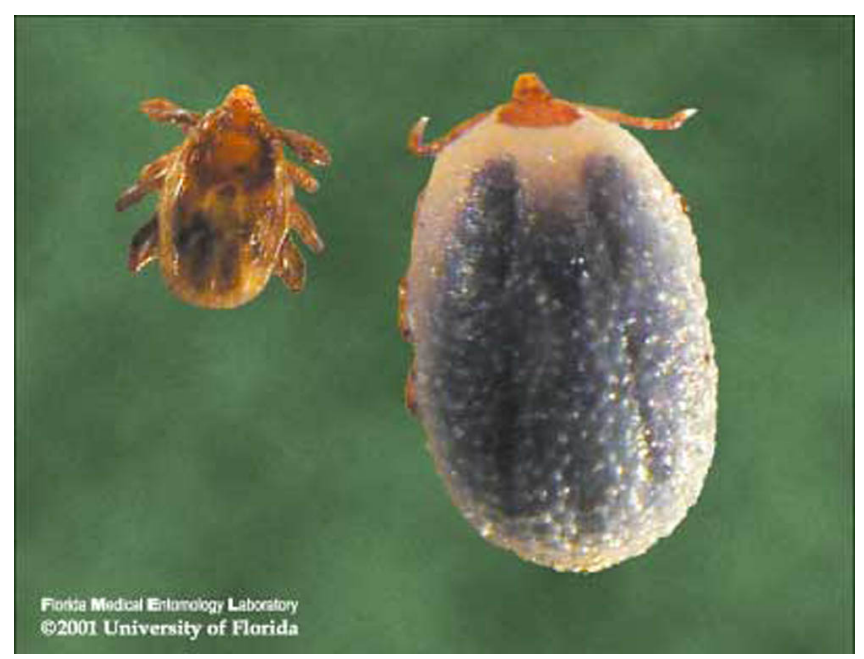

Figure 5. Engorged (left) and unengorged or flat nymphs of the brown dog tick, Rhipicephalus sanguineus Latreille. The increased size results from ingesting large volumes of blood. Credits: James Newman, University of Florida

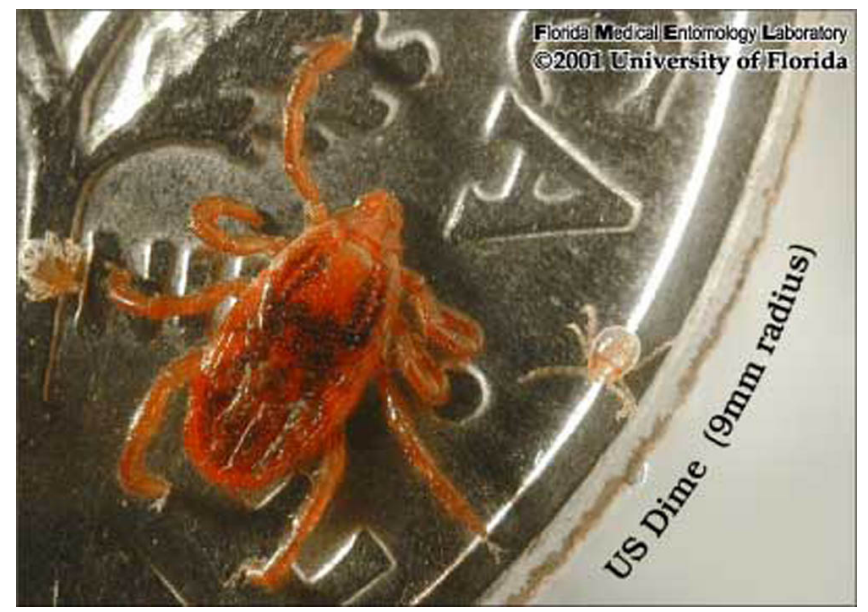

Figure 6. Nymph (larger tick) and larvae of the brown dog tick, Rhipicephalus sanguineus Latreille, on a dime.

Credits: James Newman and Leah LeFevre, University of Florida

\section{Management}

The best management strategy is prevention of infestations in the house or kennel. Discuss tick control with your veterinarian; preventing engorgement of the ticks on dogs is critical to 
management of the tick and the well-being of the dog. Treatments with fipronil (in sprays and spot-ons), amitraz (often in flea and tick collars), permethrin (sprays and shampoos) and deltamethrin (shampoos) have been reported as effective. Regular treatment will minimize the chances of a dog picking up a tick and the tick successfully feeding. Treatment will also reduce attachment by other species of tick, such as the American dog tick or the blacklegged tick. Once an infestation has started, thorough treatment of the dogs is critical and may need to be repeated several times. Follow your veterinarian's instructions and the directions on the any tick control product you use. Dogs should be examined regularly and attached ticks removed and disposed of. It may be necessary to treat the house or kennel, paying particular attention to cracks and crevices. Pest control operators should be consulted. Other mammals should be monitored and treated if necessary, but be careful about treatments used on cats. Some tick and flea treatments for dogs are poisonous in cats. People should check themselves regularly; although rare in the US this species will bite humans. DEET (found in many insect repellents) does repel these ticks, but may not be practical if an infestation is inside a house. Use according to label directions.

For additional information see the Insect Management Guide for Ticks (http://edis.ifas.ufl.edu/IG088).

The earlier the infestation is discovered and addressed, the easier it will be to control. Monitoring and grooming dogs, particularly upon return from kennels or locations where other dogs are present, is the best way to detect infestations early.

\section{Medical and Veterinary Significance}

High levels of infestation can cause skin irritation and damage in dogs, and the population can reach pest proportions in houses and kennels. In the $\mathrm{US}, R$. sanguineus is a vector of disease in dogs; canine ehrlichiosis (Ehrlichia canis) and canine babesia (Babesia canis). These rarely cause disease in humans; only a few cases are known. In dogs, symptoms of canine ehrlichiosis include lameness and fever; those for babesiosis include fever, anorexia and anemia. Both have been found in Florida. In parts of Europe, Asia and Africa $R$. sanguineus is a vector of Rickettsia conorii, known locally as Mediterranean spotted fever, boutenneuse fever, or tick typhus. $R$. sanguineus has not been shown to transmit the bacteria which causes Lyme disease.

Chapters 2 and 5 of the National Public Health Pest Control Manual (http://vector.ifas.ufl.edu/) provide details on diseases transmitted by ticks.

\section{Selected References}

Estrada-Pena, A. and F. Ascher. 1999. Comparison of an amitraz-impregnated collar with topical administration of fipronil for prevention of experimental and natural infestations by the brown dog tick (Rhipicephalus sanguineus). Journal of the American Veterinary Medical Association. 214: 1799-1803.

Folz, S. D., K. A. Ash, G. A. Conder and D. L. Rector. 1986. Amitraz: a tick and flea repellent and tick detachment drug. Journal of Veterinary Pharmacology and Therapeutics. 9: 150-156.

Fox, M. T. and T. J. Sykes. 1985. Establishment of the tropical dog tick, Rhipicephalus sanguineus, in a house in London. Veterinary Record. 116: 661-662.

Franc, M. and M. C. Cadiergues. 1999. Activity of a deltamethrin shampoo against Ctenocephalides felis and Rhipicephalus sanguineus in dogs. Veterinary Parasitology. 81: 341-346.

Koch, H. G. 1982a. Oviposition of the brown dog tick (Acari: Ixodidae) in the laboratory. Annals of the Entomological Society of America. 75: 583-586.

Koch, H. G. 1982b. Seasonal incidence and attachment sites of ticks (Acari: Ixodidae) on domestic dogs in southeastern Oklahoma and northwestern Arkansas, USA. Journal of Medical Entomology. 19: 293-298.

Koch, H. G. and M. D. Tuck. 1986. Molting and survival of the brown dog tick (Acari: Ixodidae) under different temperatures and humidities. Annals of the Entomological Society of America. 79: 11- 14. 
Kumar, S., S. Prakash, M. P. Kaushik and K. M. Rao. 1992. Comparative activity of three repellents against the ticks Rhipicephalus sanguineus and Argas persicus. Medical and Veterinary Entomology. 6: 47-50.

Rhodes, A. R. and B. R. Norment. 1979. Hosts of Rhipicephalus sanguineus (Acari: Ixodidae) in northern Mississippi, USA. Journal of Medical Entomology. 16: 488-492.

Smith, R. D., D. M. Sells, E. H. Stephenson, M. Ristic and D. L. Huxsoll. 1976. Development of Ehrlichia canis, causative agent of canine ehrlichiosis, in the tick Rhipicephalus sanguineus and its differentiation from a symbiotic richettsia. American Journal of Veterinary Research. 37: 119-126.

Sonenshine, D. E. 1993. Biology of Ticks. Vol. 2. Oxford University Press, NY. 465 pages.

Sweatman, G. K. 1967. Physical and biological factors affecting the longevity and oviposition of engorged Rhipicephalus sanguineus female ticks. Journal of Parasitology. 53: 432-445. 